\title{
Beyond reflexive measures to examine higher order pain processing in rats
}

\author{
Perry N Fuchs PhD
}

\begin{abstract}
PN Fuchs.
Beyond reflexive measures to examine higher order pain processing in rats.

Pain Res Manage 2000;5(3):215-219.

In 1968, Melzack and Casey published a pivotal paper in which they described a model of the sensory, motivational and cognitive determinants of pain. Much of Ronald Melzack's career has been dedicated to exploring this complex relationship. Of primary importance is the influence that Ron has had on the development of some of the current research interests of the present author. For instance, Ron's theoretical approach provided the underpinnings for the development of an additional behavioural testing technique in rat models of nociception that has been recently developed in the author's laboratory. The test is based on the assumption that escape and avoidance of a stimulus are clear indications that the stimulus is aversive. It is proposed that behavioural test paradigms based on this approach provide additional information beyond the traditional measures of stimulus-evoked reflexive responses. With these tests, the underlying assumption that different aspects of pain are processed by different neural substrates can be tested.
\end{abstract}

Key Words: Affect; Avoidance; Escape; Hyperalgesia; Inflammation; Motivation; Nerve ligation

\section{Le traitement de la douleur d'ordre supérieur chez le rat, au-delà des mesures autoréférentes}

RÉSUMÉ : En 1968, Melzack et Casey ont publié un article déterminant dans lequel ils définissaient un modèle des facteurs sensoriels, motivationnels et cognitifs de la douleur. Ronald Melzack a consacré une bonne part de sa carrière à explorer ce lien complexe. L'auteur tient à souligner l'influence qu'a eue Ron sur le développement de certains de ses intérêts de recherche actuels : par exemple, l'approche théorique proposée par Ron a servi de base à l'élaboration d'une autre technique d'évaluation behaviorale dans des modèles de nociception récemment élaborés dans le laboratoire de l'auteur. Ce test repose sur la prémisse selon laquelle la fuite et l'évitement d'un stimulus sont de signes clairs que le stimulus est aversif. L'auteur avance que les paradigmes des tests behavioraux fondés sur cette approche offrent des renseignements supplémentaires outre les mesures traditionnelles des réflexes évoqués par les stimuli. Grâce à ces tests, il est possible de vérifier la prémisse selon laquelle différents aspects de la douleur sont traités par différents substrats neuraux.

\begin{abstract}
A great deal of inspiration for my current research activities comes from a paper that was published by Melzack and Casey (1), in which a model of the sensory, motivational and cognitive determinants of pain was presented. It was proposed that neural structures that compose the brain stem reticular formation and limbic system are involved in the emotional and motivational determinant of pain, and that this system was separate from the neural structures subserving the sensory and discriminative dimension of pain. A glance at Ron's research activities since the publication of this paper reveals his continual effort at exploring this complex relationship. For instance, the McGill Pain Questionnaire was designed to quantify sensory, affective and evaluative as-
\end{abstract}

pects of patients' subjective pain experience (2). Ron has also been keenly aware of the influence that psychological factors have on the individual's pain experience (3). In addition, there has been continuing effort at understanding the role of limbic system structures in pain processing (4-7).

The original proposal by Melzack and Casey (1) is still widely regarded. However, examination of the literature reveals that the hypothesis of separate, interacting systems that process sensory/discriminative and emotional/motivational determinants of pain have not been rigorously examined. A major factor for lack of direct testing is most likely related to the commonly used behavioural testing methods in rodent models of nociception. For instance, following nerve injury, 


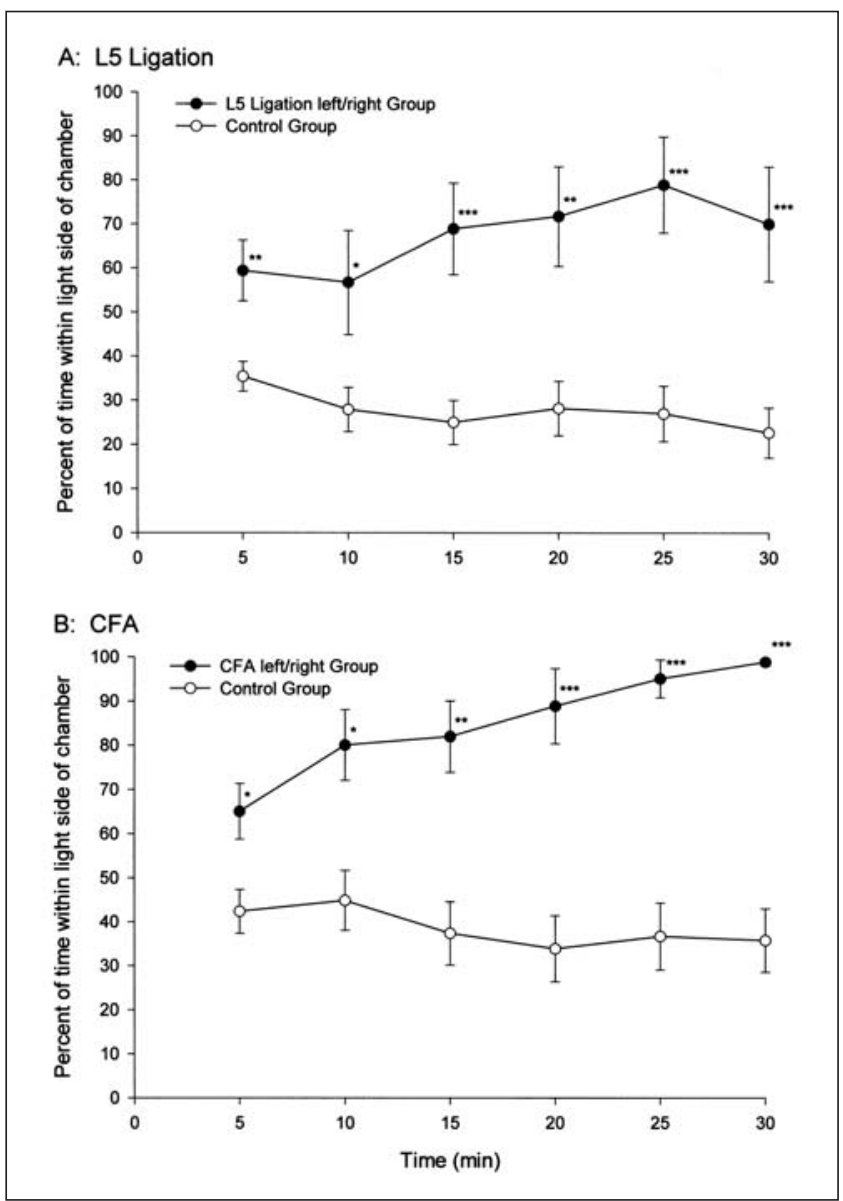

Figure 1) Percentage of time (mean \pm SEM) for each 5 min test interval spent in the light side of the test chamber for animals following A peripheral nerve damage (L5 ligation) or B inflammation (subcutaneous complete Freund's adjuvant [CFA]). When mechanical stimulation of the ligated or inflamed paw was associated with the preferred dark area of the chamber (L5 ligation left/right group; CFA left/right group) animals rapidly began to spend an increased amount of time in the light area of the chamber. The control group for both the L5 ligation and the CFA inflammation conditions consisted of a combination of three separate groups. In both conditions, one group of control subjects did not have an injury and was administered the mechanical stimulus in an identical manner as the experimental group. The two additional control groups consisted of subjects that had an injury, but the stimulus was not paired specifically with either side of the chamber. One of these groups always received mechanical stimulation to the ligated or inflamed paw; the other control group always received mechanical stimulation to the contralateral nonligated or inflamed paw. Analysis revealed no significant difference among the three control groups for the two pain models. ${ }^{*} \mathrm{P}<0.05$; ${ }^{*} \mathrm{P}<0.01 ;{ }^{*} * \mathrm{P}<0.001$. Reproduced with permission from reference 12

animals display behaviours that are thought to reflect clinical conditions of neuropathic pain (8-10). Quantification of stimulus-evoked nociceptive behaviours is based almost exclusively on withdrawal thresholds. The typical left ward shift in the stimulus-response function after peripheral nerve injury or the induction of an inflammatory condition is experimental evidence for allodynia and hyperalgesia. A treat- ment with an antinociceptive effect results in attenuation of the leftward shift in the stimulus-response function. Manipulations (ie, pharmacological) that fail to attenuate the leftward shift in the stimulus-response function are assumed to lack antinociceptive properties.

However, there might be instances in which additional measures that are not based on withdrawal responses can provide evidence for antinociceptive properties in the absence of an attenuation in the leftward shift of the stimulus-response function. For instance, psychophysical evidence indicates that morphine can selectively modulate the affective dimension of pain without altering the sensory aspect (11). Clinically, patients receiving morphine for pain control sometimes report that the pain is still present but that it does not bother them as much. I propose that this aspect of the experience cannot be measured with stimulus-evoked withdrawal tests but can be quantified using additional behavioural test paradigms. I present one such approach and examine some results of studies performed in my research laboratory.

\section{METHODS AND RESULTS}

The use of behavioural tests to measure the aversive nature of nociceptive behaviour in rats - the escape/avoidance test paradigm

As mentioned above, one of the most common behavioural paradigms in assessing nociceptive behaviour is the measurement of stimulus-evoked pain. In this paradigm, the force that is required to produce withdrawal of the limb, or the latency to withdrawal the limb from a thermal stimulus, is measured. There is little doubt that testing based on withdrawal responses is of extreme importance. For instance, the withdrawal method has been useful for revealing certain aspects of the nociceptive system and allowing a fast initial screen for potentially useful analgesic compounds. It becomes more problematic when it is assumed that manipulations to neural structures thought to be involved in emotional aspects of behaviour that decrease stimulus-evoked behaviour reflect changes that occur in the affective-motivational dimension of pain processing (5). This assumption has not been rigorously tested in animal models.

To test directly the role of different neural substrates on the emotional aspect of nociceptive behaviour, additional measures in which the affective and motivational dimension of pain can be dissociated from sensory and discriminative aspects are needed. One such approach is the use of operant techniques that measure escape and avoidance of animals (12-14). The assumption is that escape and/or avoidance of a noxious stimulus is a clear indication that the stimulus is aversive.

A behavioural test method based on this assumption has been recently reported (12). In this paradigm, the animals are allowed to 'choose' where the mechanical stimulus is applied - the ligated and/or inflamed paw, or the contralateral control paw. The basic paradigm requires the use of a chamber that is equally divided into a dark side and a light side. Under normal conditions, rats' natural preference is for the dark area of the environment. During behavioural testing, a mechanical 
stimulus (476 mN von Frey monofilament) is applied to the treated paw when the animal is in the dark area or to the nontreated contralateral paw when the animal is in the light area of the chamber. The amount of time that animals spend in the light side of the chamber is recorded. Control animals spend about $20 \%$ to $40 \%$ of the time in the light side of the chamber (Figure 1). However, the L5-ligated and subcutaneous complete Freund's adjuvant-treated experimental groups demonstrate escape and avoidance behaviour toward the dark side of the chamber, and a shift in preference toward the light side of the chamber. The escape and avoidance behaviour illustrated in Figure 1 supports the notion that mechanical stimulation of the treated paw during a neuropathic or inflammatory pain condition is aversive and that, when given a choice, animals will perform purposeful behaviour to minimize stimulation of the afflicted body region.

\section{Morphine and gabapentin decrease mechanical hyperalgesia, and escape and/or avoidance behaviour}

To test further the validity of the escape/avoidance test paradigm, the effect of two commonly used analgesic agents, morphine and gabapentin, was tested (15). Decreased mechanical sensitivity was measured using the traditional stimulus-evoked threshold method with von Frey monofilaments three days after L5 nerve ligation immediately before and then $30 \mathrm{~min}$ after the administration of different doses of morphine $(1 \mathrm{mg} / \mathrm{kg}$ or $10 \mathrm{mg} / \mathrm{kg})$ or gabapentin $(30 \mathrm{mg} / \mathrm{kg}$ or $90 \mathrm{mg} / \mathrm{kg}$ ). Compared with the vehicle-treated, L5-ligated group, both morphine and gabapentin decreased the enhanced response to mechanical stimuli in a dose-dependent manner (Figure 2A). Of primary interest, however, is the additional finding that both morphine and gabapentin also attenuated the escape and/or avoidance behaviour. Vehicletreated, L5-ligated animals demonstrated an almost identical pattern of escape and/or avoidance behaviour as the L5ligated animals illustrated in Figure 1A. Morphine- $(1 \mathrm{mg} / \mathrm{kg})$ and gabapentin- $(30 \mathrm{mg} / \mathrm{kg}$ and $90 \mathrm{mg} / \mathrm{kg})$ treated, L5-ligated animals displayed less time in the light area of the chamber than the vehicle-treated, L5-ligated animals (Figure 2B). These results indicate that manipulations that decrease hyperalgesia also attenuate escape and/or avoidance behaviour. In other words, the behavioural test paradigm reveals that, if the experimental condition is less 'painful', then mechanical stimulation of the afflicted region is less aversive.

\section{Lesions of the cingulate cortex: Differential effect on hyperalgesia, and escape and/or avoidance behaviour} The hypothesis that limbic system structures are involved in the aversiveness of stimulus-evoked pain has also been examined using this test paradigm. It has been suggested that the anterior cingulate cortex (ACC) is a critical structure in processing pain, especially with regard to affect and motivation. This conclusion is based on three primary lines of evidence. First, electrophysiological studies have revealed nociceptive neurons in the rat and rabbit ACC that have very large receptive fields - consistent with the notion that this region is involved in encoding intensity rather than spatial dis-

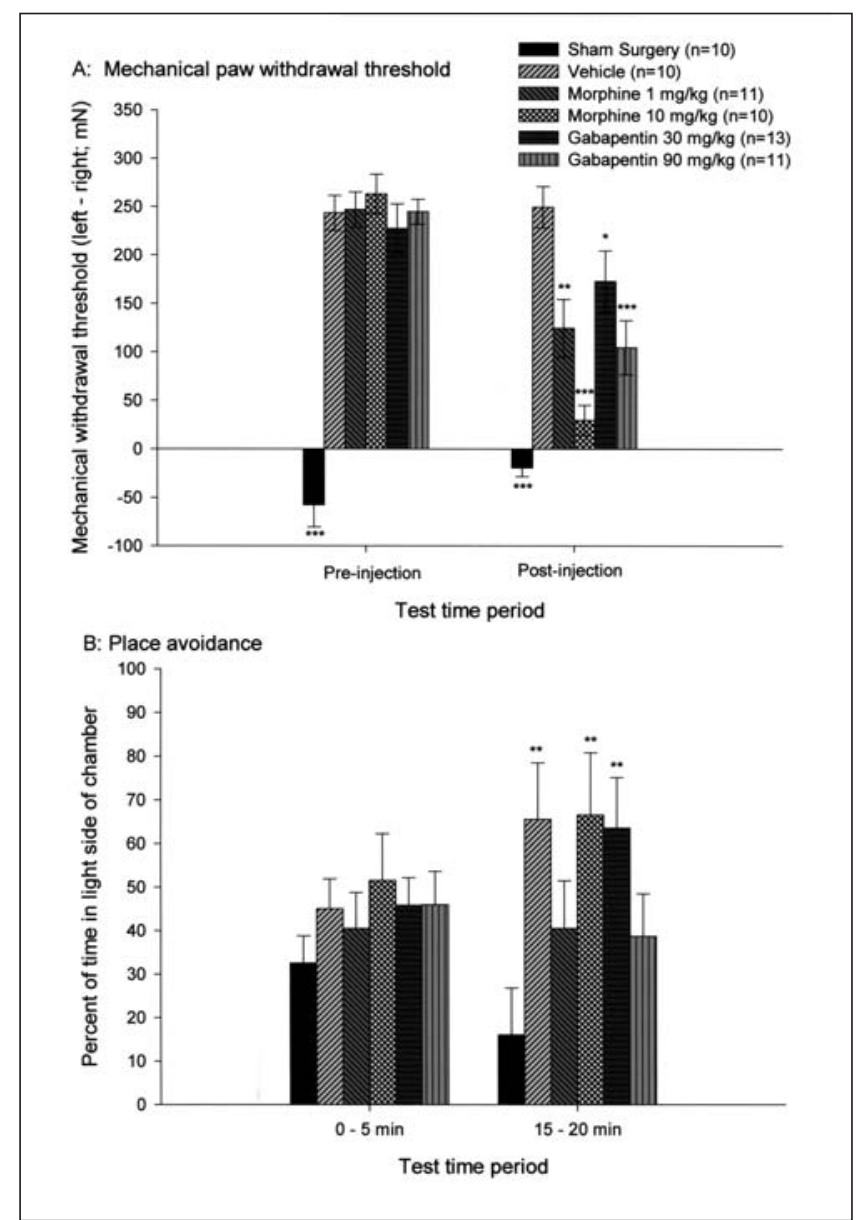

Figure 2) A Mean \pm SE mechanical paw withdrawal threshold (left paw/right paw) for animals that did not receive L5 ligation (sham surgery) or received different doses of different compounds following L5 ligation. Mechanical paw withdrawal thresholds for the preinjection and postinjection time periods were analyzed using one-way ANOVA on the right/left paw difference score for each animal at each time point followed by post hoc comparison (least significant difference) for group differences. ${ }^{*} \mathrm{P}<0.05 ;{ }^{*} \mathrm{P}<0.01 ;{ }^{* * *} \mathrm{P}<0.001$ compared with vehicle control. B Mean \pm SEM percentage of time spent within the light side of the chamber from 0 to $5 \mathrm{~min}$ and 15 to $20 \mathrm{~min}$ for animals that did not receive L5 ligation (sham surgery) or received different doses of different compounds following L5 ligation. The duration of time spent in the light side of the chamber was analyzed for group difference using one-way ANOVA for the 0 to $5 \mathrm{~min}$ and the 15 to $20 \mathrm{~min}$ time periods followed by post hoc comparison (LSD) for group differences. $* * \mathrm{P}<0.01$ compared with sham surgery control. Reproduced with permission from reference 15

crimination (16). Second, human imaging studies have correlated the unpleasantness of pain with ACC activation $(17,18)$. Third, cingulotomy provide significant pain relief in humans (19-21). The effectiveness of this procedure has been attributed to the interruption of the cingulate gyrus concerned with the emotional component of pain (22). Indeed, patients with ACC lesions report that the intensity of their pain remains but that it is less bothersome (23).

The escape/avoidance paradigm has been used to determine whether the same pattern of behavioural results could 
be obtained from the rat. It was predicted that lesions of the rat ACC would decrease the aversiveness of pain without altering the mechanical hyperalgesia. These results confirm this hypothesis (LaGraize et al, unpublished data). First, bilateral ACC electrolytic lesions failed to reverse the decrease in mechanical withdrawal threshold after L5 ligation. However, the electrolytic lesions significantly attenuated the shift from the dark side of the test chamber relative to the nonlesioned L5-ligated control group. These results reflect the clinical reports of patients who indicate that, after ACC lesions, the intensity of the pain remains but that it is less bothersome. Although alternative explanations of the data have yet to be excluded (ie, that ACC lesions interrupt memory processes that are critical for the acquisition of the association), this finding provides preliminary evidence to support the original proposition by Melzack and Casey (1) that limbic system structures have different modulatory effects on sensory/discriminative, and emotional/motivational dimensions of pain.

\section{DISCUSSION}

I have described a behavioural test paradigm and some additional experimental results based on operant techniques to explore the complex nature of pain in rat models of nociception. Unlike traditional threshold measurement techniques, the general paradigm outlined above provides animals with the opportunity to perform purposeful behaviour to escape and/or avoid mechanical stimulation by a von Frey monofilament to the hyperalgesic body region. The assumption is that escape and avoidance behaviour is an indication that animals find the mechanical stimulus to be aversive. This is analogous to a patient who demonstrates guarding behaviour and avoidance of environmental conditions that might exacerbate the severe discomfort associated with causalgia or other clinical pain syndromes. Although the present approach is by all accounts not the only paradigm that can be used, it is a very important initial step in developing operant behavioural test paradigms to unravel the complex processing of nociceptive information in supraspinal neural substrates.

The dissociation of different aspects of pain in basic research has been suggested by showing differential effects of the same manipulation on different pain assays (ie, tail-flick

\section{REFERENCES}

1. Melzack R, Casey KL. Sensory, motivational, and central-control determinants of pain. In: Kenshalo DR, ed. The Skin Senses. Springfield: CC Thomas, 1968

2. Melzack R. The McGill Pain Questionnaire: major properties and scoring methods. Pain 1975;1:277-99.

3. Taenzer P, Melzack R, Jeans ME. Influence of psychological factors on postoperative pain, mood and analgesic requirements. Pain 1986;24:331-42.

4. Fuchs PN, Balinsky M, Melzack R. Electrical stimulation of the cingulum bundle and surrounding cortical tissue reduces formalin-test pain in the rat. Brain Res 1996;743:119-23.

5. Fuchs PN, Melzack R. Analgesia induced by morphine microinjection into the lateral hypothalamus of the rat. Exp Neurol 1995; $134: 277-80$

6. McKenna JE, Melzack R. Analgesia produced by lidocaine microinjected into the dentate gyrus. Pain 1992;49:105-12. to measure the sensory/discrimination and the formalin test to measure the emotional/affective). For example, lidocaine injection into the lateral hypothalamus, cingulum bundle and reticular formation reduces pain in the formalin assay but not the foot-flick or tail-flick assays (24-26). Lesions of the periaqueductal grey attenuate morphine analgesia in the tailflick test but not in the formalin test (27). The advantage of the present approach is that it can be used to evaluate different dimensions of pain within the same pain assay.

The belief of the need for behavioural testing beyond stimulus-evoked reflexive behavioural procedures is a partial result of the time that I spent as a postdoctoral research fellow with Ron Melzack. In fact, my theoretical approach is best reflected by Ron's statement (1) that pain

\section{becomes overwhelming, demands immediate attention, and disrupts ongoing behaviour and thought. It motivates or drives the organism into activity aimed at stopping the pain as quickly as possible. To consider only the sensory features of pain, and ignore its affective and motivational properties, is to look at only part of the problem.}

Additional experiences during my time at McGill University, Montreal, Quebec, have made a more general impact on my desire to understand pain and the impact that it can have on a person's quality of life. During weekly pain clinic meetings at the Montreal General Hospital, Ron (as well as the other colleagues at the Montreal General Hospital pain clinic) always showed a tremendous degree of quiet compassion for the well-being of patients. Although many patients thought that there were no more options, Ron was always reassuring and would spend an extraordinary amount of time considering an appropriate course of action. My impressions are not unique but are shared by all who have had the opportunity to talk and work with him during the course of his remarkable career.

ACKNOWLEDGEMENTS: I acknowledge Renee R Donahue, Christopher J LaBuda and Stacey C LaGraize for discussion and time spent collecting data. Supported in part by the Texas Advance Research (Technology) Program.
7. Vaccarino AL, Melzack R. Temporal processes of formalin pain; differential role of the cingulum bundle, fornix pathway and medial bulboreticular formation. Pain 1992;49:257-71.

8. Bennett GJ, Xie Y-K. A peripheral mononeuropathy in rat that produces disorders of pain sensation like those seen in man. Pain 1988;33:87-107.

9. Kim SH, Chung JM. An experimental model for peripheral neuropathy produced by segmental spinal nerve ligation in the rat. Pain 1992;50:355-63.

10. Seltzer Z, Dubner R, Shir Y. A novel behavioral model of neuropathic pain disorders produced in rats by partial sciatic nerve injury. Pain 1990;43:205-18.

11. Price DD, Von Der Gruen A, Miller J, Rafii A, Price CA. Psychophysical analysis of morphine analgesia. Pain 1985;22:261-9.

12. LaBuda CJ, Fuchs PN. A behavioral test paradigm to measure the 
aversive quality of inflammatory and neuropathic pain in rats. Exp Neurol 2000;163:490-4.

13. Mauderli AP, Acosta-Rua A, Vierck CJ Jr. An operant assay of thermal pain in conscious, unrestrained rats. J Neurosci Methods 2000;97:19-29.

14. Yeomans DC, Cooper BY, Vierck CJ Jr. Comparisons of dosedependent effects of systemic morphine on flexion reflex components and operant avoidance responses of awake non-human primates. Brain Res 1995;670:297-302.

15. LaBuda CJ, Fuchs PN. Morphine and gabapentin decrease mechanical hyperalgesia and escape/avoidance behavior in a rat model of neuropathic pain. Neurosci Lett. 2000;290:137-40.

16. Sikes RW, Vogt BA. Nociceptive neurons in area 24 of rabbit cingulate cortex. J Neurophysiol 1992;68:1720-32.

17. Rainville P, Duncan GH, Price DD, Carrier B, Bushnell MC. Pain affect encoded in human anterior cingulate but not somatosensory cortex. Science 1997;277:968-71.

18. Tölle TR, Kaufmann T, Siessmeier T, et al. Region-specific encoding of sensory and affective components of pain in the human brain: a positron emission tomography correlation analysis. Ann Neurol 1999;45:40-7.

19. Ballintine HT, Cassidy WL, Flanagan NB, Marino R. Stereotaxic anterior cingulotomy for neuropsychiatric illness and intractable pain. J Neurosurg 1967;26:488-95.
20. Pillay PK, Hassenbusch SJ. Bilateral MRI-guided stereotactic cingulotomy for intractable pain. Stereotact Funct Neurosurg 1992;59:33-8.

21. Wong ET, Gunes S, Gaughan E, et al. Palliation of intractable cancer pain by MRI-guided cingulotomy. Clin J Pain 1997;13:260-3.

22. Martinez SN, Bertrand C, Molina P, Perez-Colon JM. Alteration of pain perception by stereotaxic lesions of fronto-thalamic pathways. Confin Neurol 1975;37:113.

23. Corkin S, Hebben N. Subjective estimates of chronic pain before and after psychosurgery or treatment in a pain unit. Pain 1981;1(Suppl):S150.

24. Tasker RAR, Choinière M, Libman SM, Melzack R. Analgesia produced by injection of lidocaine into the lateral hypothalamus. Pain 1987;31:237-48.

25. Vaccarino AL, Melzack R. Analgesia produced by injection of lidocaine into the anterior cingulum bundle of the rat. Pain 1989;39:213-9.

26. Vaccarino AL, Melzack R. Temporal processes of formalin pain: differential role of the cingulum bundle, fornix pathway and medial bulboreticular formation. Pain 1992;49:257-71.

27. Abbott FV, Melzack R, Samuel C. Morphine analgesia in the tail-flick and formalin pain tests is mediated by different neural substrates. Exp Neurol 1982;75:644-51. 


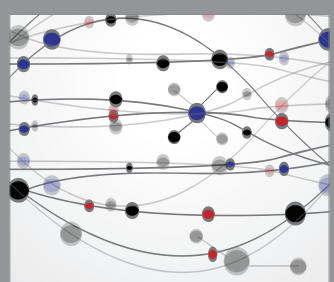

The Scientific World Journal
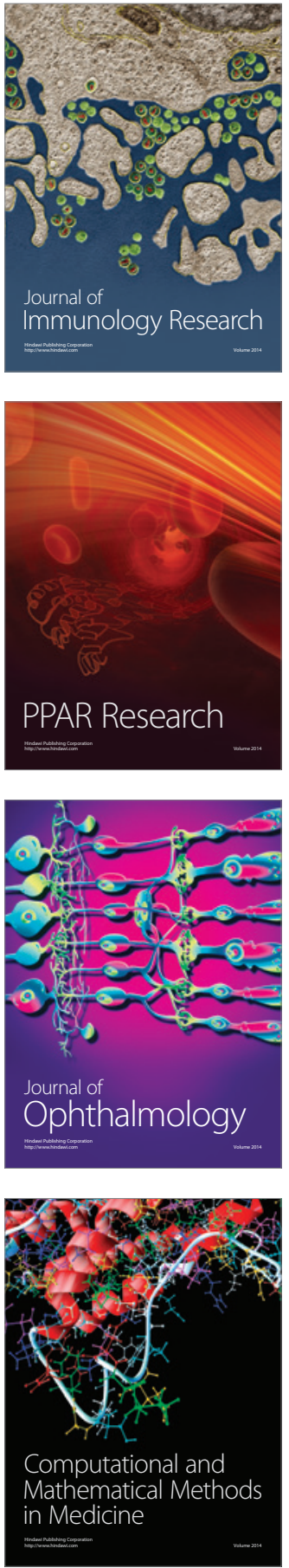

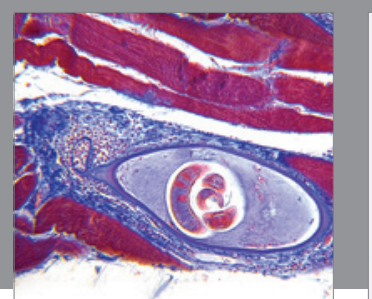

Gastroenterology Research and Practice

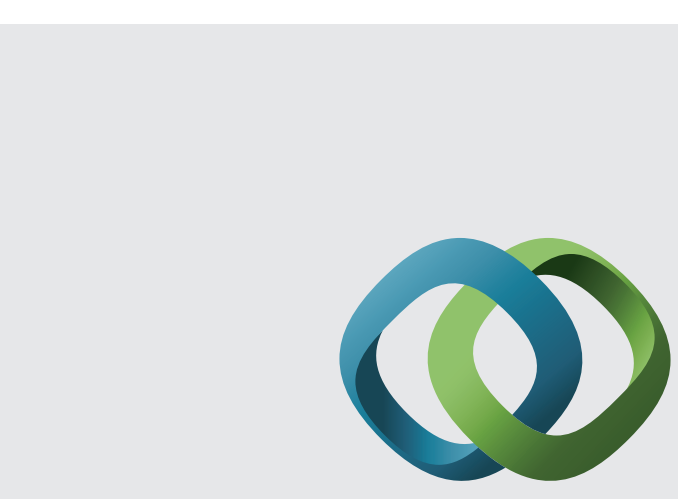

\section{Hindawi}

Submit your manuscripts at

http://www.hindawi.com
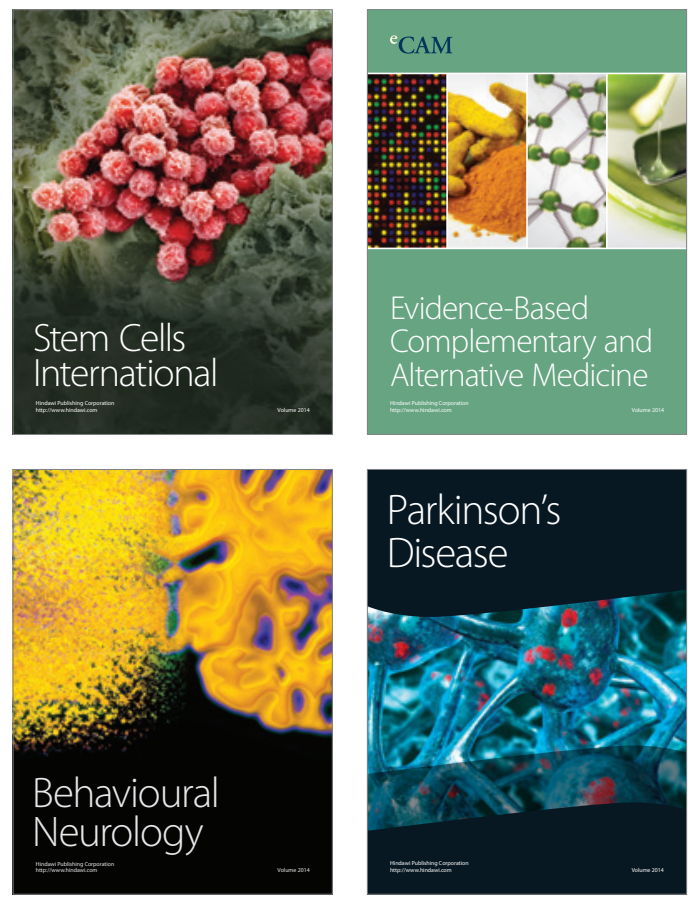
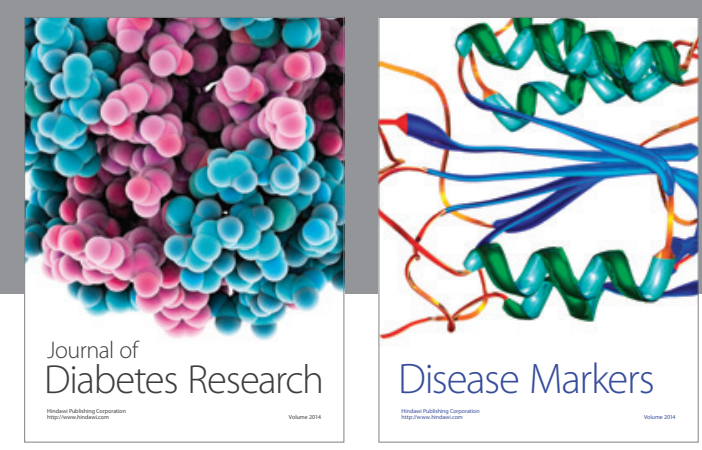

Disease Markers
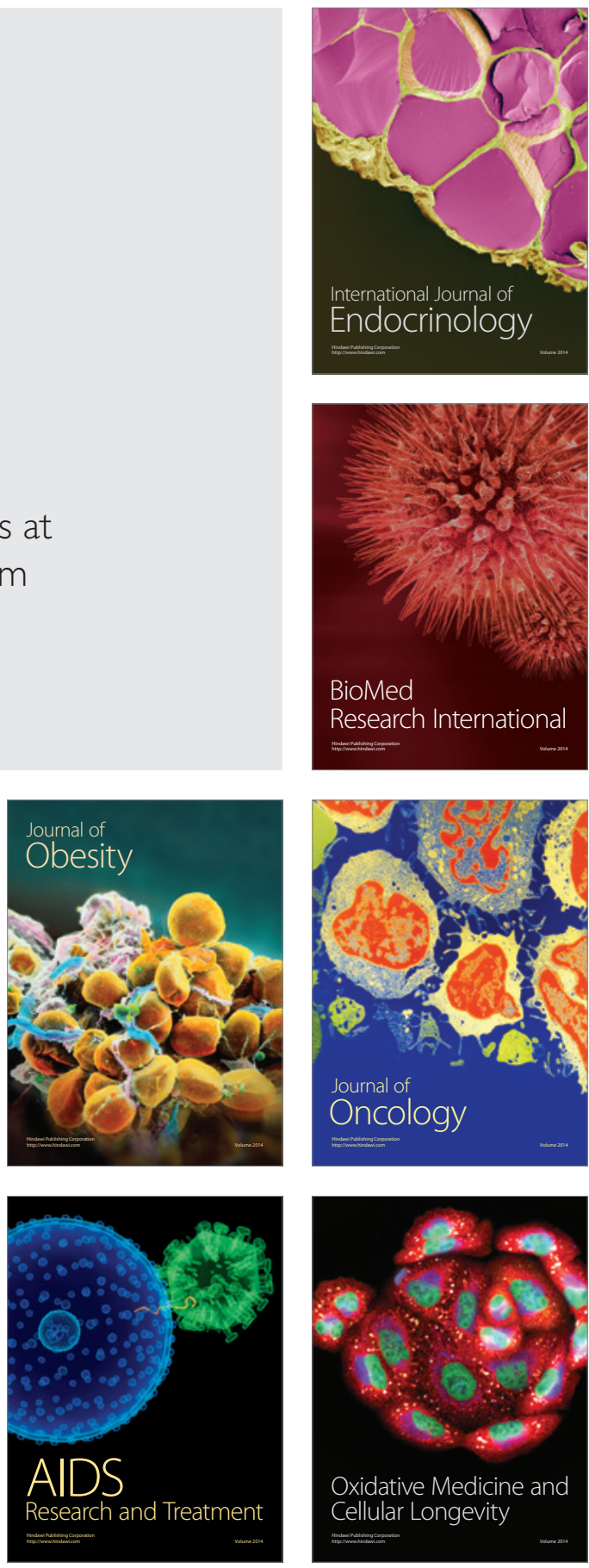